\title{
3-D printing of chitosan-calcium phosphate inks: rheology, interactions and characterization
}

\author{
Published in Journal of Materials Science : Materials in Medicine (2019) 30 p. 6 \\ https://doi.org/10.1007/s10856-018-6201-y
}

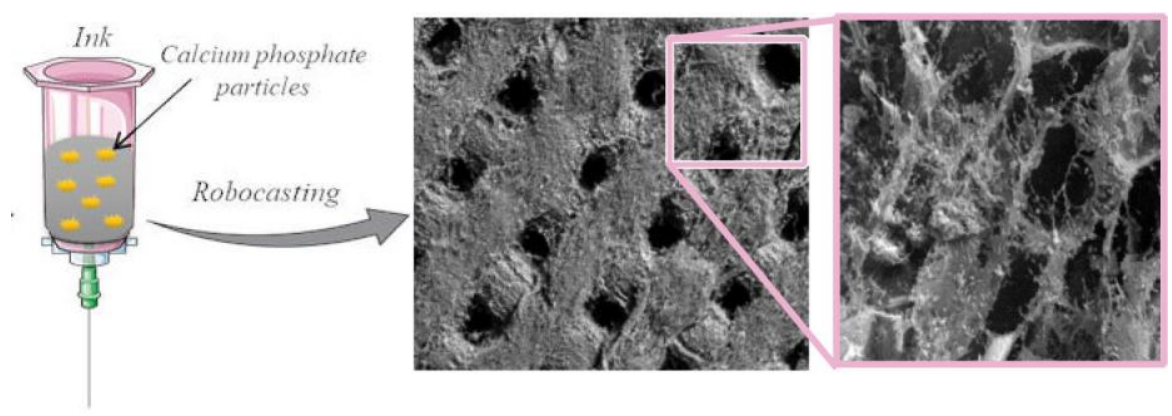

Silvia Stella Ramirez Caballero ${ }^{1,2}$, Eduardo Saiz ${ }^{3}$, Alexandra Montembault,*, Solène Tadier $^{1}$, Eric Maire ${ }^{1}$, Laurent David ${ }^{2}$, Thierry Delair ${ }^{2}$, Laurent Grémillard ${ }^{1, *}$

${ }^{1}$ Univ Lyon, INSA Lyon, MATEIS UMR CNRS 5510, Bât. Blaise Pascal, 7 Avenue Jean Capelle, Villeurbanne, France

2 Univ Lyon, Université Claude Bernard Lyon 1, Ingénierie des Matériaux Polymères, IMP@Lyon1, CNRS UMR 5223, 15, bd A. Latarjet, F-69622, Villeurbanne, France

${ }^{3}$ Centre of Advanced Structural Ceramics, Department of Materials, Imperial College London, SW7 2AZ, UK

* Corresponding authors:

Laurent Grémillard (laurent.gremillard@insa-lyon.fr ; +33 4724381 52) and

Alexandra Montembault (alexandra.clayer-montembault@univ-lyon1.fr ; +33 47243 16 06)

Orcid numbers :

Eduardo Saiz : 0000-0002-2127-7282

Solène Tadier: 0000-0002-7660-1705

Thierry Delair: 0000-0003-0983-4557

Laurent David: 0000-0003-3632-8537

Laurent Gremillard : 0000-0001-7258-6483 


\begin{abstract}
Bone substitute fabrication is of interest to meet the worldwide incidence of bone disorders. Physical chitosan hydrogels with intertwined apatite particles were chosen to meet the biophysical and mechanical properties required by a potential bone substitute. A set up for 3$\mathrm{D}$ printing by robocasting was found adequate to fabricate scaffolds. Inks consisted of suspensions of calcium phosphate particles in chitosan acidic aqueous solution. The inks are shear-thinning and consist of a suspension of dispersed platelet aggregates of dicalcium phosphate dihydrate in a continuous chitosan phase. The rheological properties of the inks were studied, including their shear-thinning characteristics and yield stress. Scaffolds were printed in basic water/ethanol baths to induce transformation of chitosan-calcium phosphates suspension into physical hydrogel of chitosan mineralized with apatite. Scaffolds consisted of a chitosan polymeric matrix intertwined with poorly crystalline apatite particles. Results indicate that ink rheological properties could be tuned by controlling ink composition: in particular, more printable inks are obtained with higher chitosan concentration $\left(0.19 \mathrm{~mol} \cdot \mathrm{L}^{-1}\right)$.
\end{abstract}

\title{
KEYWORDS
}

Robocasting, Hydroxyapatite, Chitosan physical hydrogels, Biocomposites, Bone graft substitutes

\section{INTRODUCTION}

Worldwide occurrence of bone disorders is a social problem of major concern due to the general ageing of population, the growing incidence of obesity, and to the low physical activity. During the last four decades, bone tissue engineering has been a constantly growing research area, which purpose is to find solutions for bone substitution and regeneration by a synergistic combination of biomaterials, cells and factor therapies [1].

An ideal bone substitute would be a material that temporary replaces bone tissue, thus ensuring its mechanical function, while promoting bone formation and growth concurrently to its bioresorption. Resulting from these requirements, a compromise should be met between structural and chemical complexity, ease of fabrication, ease of handling by the surgeon and costs [2]. Since it is difficult to find a single material that meets all the properties required by a bone substitute, an alternative is to combine materials with complementary properties, for example, bioceramics and biopolymers [1, 3-9]. A composite material composed of calcium phosphates (inorganic, bioceramics) and chitosan (organic, biopolymer) should provide a good substrate for bone growth [10-13].

Chitosan is a non-toxic and biodegradable natural polymer [14-17]. It is known to promote the proliferation of osteoblasts and mesenchymal cells and in-vivo vascularization [18-20]. Chitosan has also been reported to be antimicrobial to fungi, parasites and bacteria [21]. Apatite is a calcium phosphate bioceramic with composition and structure close to the inorganic part of the extracellular matrix of bone. Apatite is osteoconductive $[22,23]$ and may be resorbed by bone cells, leaving enough space for new bone growth [2]. Since the combination of both materials might offer both angiogenicity and osseoconductivity in a single composite, such a composite may prove useful to fill large bone defects for which vascularization of the core of the bone filler is a condition sine qua non for success.

Reported articles deal with the fabrication of chitosan-calcium phosphates composites. They were shaped as membranes, films, scaffolds, injectable materials, multilayers films and particles [20,24]. However, pore size, shape, and pore interconnectivity at different scales $(30-500 \mu \mathrm{m})$ cannot be fully controlled using classical processing methods [25]. Inversely, the use of additive 
manufacturing techniques such as robocasting should allow the control of the pore morphology and size in the micron-scale and above.

Robocasting (also called Direct Ink Writing) is an extrusion-based additive manufacturing technique, in which an ink is pumped from a syringe to be delivered through a nozzle. A robot determines the nozzle position where the ink is extruded, drawing out the shape of the printed object [26]. The ink should meet two basic conditions: 1) it should flow under mild stress to avoid excessive pressure during pumping, but at the same time; 2) it should recover enough stiffness just after extrusion, when the stress is released, to retain the shape and solidify to bear its own weight and the weight of successive layers extruded on top [27-29] and to resist capillary pressure [30]. This means that a precise control of the rheological properties of the ink is crucial $[29,31,32]$. Whatever the ink composition (polymer, ceramic or composite), one approach to reach these properties is the use of chemical crosslinking agents in the ink formulation [29]. However, chemical crosslinking agents could complicate the control of ink properties and moreover, they may be toxic to the patient. Another approach to reach the rheological properties is the controlled combination of calcium phosphate powders of specific features with chitosan solution [31].

Up to now, all research performed on robocasting of chitosan-calcium phosphates [29, 31, 32] aimed at fabricating dry, architectured sponges (thus involving a freeze-drying step to get the final material). The alternative explored in this work, is to simultaneously form a chitosan physical hydrogel to solidify the ink and to precipitate intertwined particles of calcium phosphate. The intertwining and the interactions between the two phases would also contribute to crosslink the network, in line with the idea to avoid toxic cross-linkers and extra freeze-drying step. In addition, this approach resembles the physiological mineralization process of bones, since also in our case the formation of calcium phosphate occurs in a hydrated natural polymer matrix.

Rheological characteristics of chitosan-calcium phosphate suspensions depend upon the physicochemical interactions occurring between chitosan chains, ions and particles, thus in particular they may be impacted by $\mathrm{pH}$ [33]. Such interactions are mainly hydrogen bonds, electrostatic forces (attractive and repulsive) and polymer chain entanglements [33]. In short, three main interactions may affect the cross-linking state of the inks, thus their rheological properties.

- First, calcium ions and electron donor atoms (nitrogen and oxygen) of chitosan molecule form coordination bond, increasing cross-linking [34].

- Second, orthophosphate ions and amine groups can be involved in attractive electrostatic interactions [35, 36], again inducing chitosan chain cross-links.

- Third, the ionic strength may promote chains disentanglement. Indeed, chitosan is soluble in acidic aqueous media $(\mathrm{pH} \leq 6)$ thanks to the protonation of the primary amines of the glucosamine residues [37]. However, salts, sources of calcium and orthophosphate ions contribute to the ionic strength of the medium, which in turn, may screen electrostatic interactions [33], thus weakening the repulsive forces between polymer chains; as a result chitosan chains become more flexible and tend to disentangle [33].

The increase of $\mathrm{pH}$ in appropriate physico-chemical conditions leads to the formation of physical chitosan hydrogels. In neutral or alkaline aqueous solutions, amine groups are neutralized (deprotonated), reducing the repulsion between polymer chains. As a consequence, polymer chains can physically cross-link [37, 38].

Thus, the general objective of this work is to obtain architectured physical hydrogels of chitosan with intertwined (or entrapped) apatite particles, via robocasting, using a $\mathrm{pH}$ change to get the final material. This involves the preparation inks composed of chitosan and calcium phosphates for printing and the characterization of their rheological features, to find a processing window for robocasting. The chemical compositions of these inks are correlated to their structure (via a study of their rheological properties) to investigate possible synergistic physico-chemical interactions (between ions, mineral phase and chitosan chains), as previously detailed. Finally, an experimental protocol to fabricate scaffolds of mineralized chitosan hydrogels by 3-D printing-robocasting is proposed. 


\section{MATERIALS and METHODS}

The fabrication of the biocomposite comprises ink formulation, preparation and physicochemical characterization, followed by 3-D printing of inks and physico-chemical characterization of the obtained scaffolds (Figure 1).

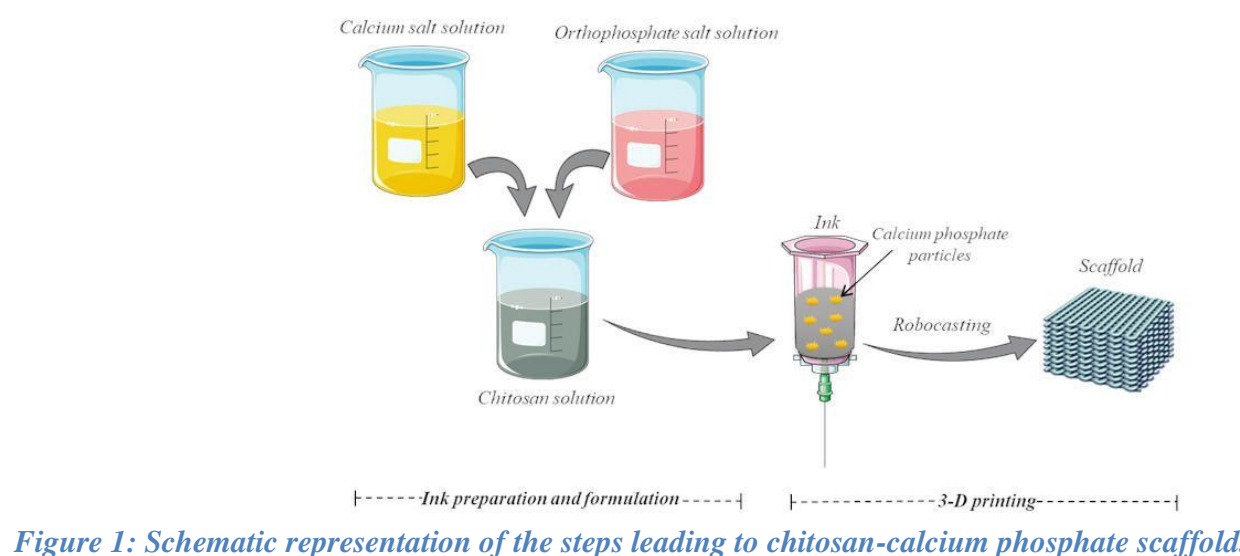

\section{Inks preparation and formulation}

Inks consisted of suspensions of calcium phosphate particles in a chitosan acidic aqueous solution. Chitosan powder produced from squid pens and supplied by Mahtani Chitosan Pvt. Ltd (batch type 114, No S3 20110121) was characterized with standard procedures [37]. The degree of acetylation, corresponding to the molar fraction of acetylated units within the polymer chains, was close to $5 \%$; the weight-average molar mass and dispersity were $M_{w}=550 \mathrm{~kg} \cdot \mathrm{mol}^{-1}$ and $Ð=1.9$, respectively. Chitosan acetate solutions of various repeat unit concentrations $(0.15 \mathrm{M}(2.4 \mathrm{wt} \%), 0.17 \mathrm{M}$ $(2.8 \mathrm{wt} \%)$ and $0.19 \mathrm{M}(3.1 \mathrm{wt} \%)$ were prepared by adding chitosan powder to acetic acid (Carlo Erba Reagents, CAS 64-19-7, assay 99.9\%) aqueous solutions. The amount of acetic acid was adjusted to match the stoichiometric protonation of $-\mathrm{NH}_{2}$ sites of chitosan. The as-prepared chitosan solution was mixed in a Thinky ARE-250 planetary mixer at $2000 \mathrm{rpm}$ in mixing cycles of 5 minutes until complete dissolution.

Inorganic salt solutions were prepared by dissolving $\mathrm{Ca}\left(\mathrm{NO}_{3}\right)_{2} .4 \mathrm{H}_{2} \mathrm{O}$ (Sigma-Aldrich, CAS 13477 $34-4$, assay $\geq 99 \%$ ) and $\left(\mathrm{NH}_{4}\right)_{2} \mathrm{HPO}_{4}$ (Sigma-Aldrich, CAS 7783-28-0, assay $\geq 99 \%$ ) in water, $\mathrm{pH}$ 4.5 and 8.5 respectively. Initial concentrations are reported in Table 1. Calcium and orthophosphate solutions were added simultaneously into chitosan solutions and mixed in the planetary mixer at $2000 \mathrm{rpm}$ in mixing cycles of 5 minutes until obtaining chitosan-calcium phosphate homogenous suspensions.

Chitosan solutions and salt solutions were mixed in such volume proportion as to obtain different proportions of inorganic to organic components (in/or, equation 1) while maintaining the calcium to phosphorous molar ratio $(\mathrm{Ca} / \mathrm{P})$ constant to 1.67 (i.e. the same value as in stoichiometric hydroxyapatite $\left.\mathrm{Ca}_{10}\left(\mathrm{PO}_{4}\right)_{6} \mathrm{OH}_{2}\right)$. Thus, inks were formulated according to the ratios defined in equation (1). Three chitosan solutions of different polymer concentrations, without any $\mathrm{Ca}$ and $\mathrm{P}$ were prepared as references. The compositions of inks are reported in Table 1 . Throughout the article, the inks will be referred to as Inn-xy, were nn represents the concentration of chitosan ( $\mathrm{nn}=$ 15,17 or 19 for $[\mathrm{CS}]=0.15,0.17$ or $0.19 \mathrm{~mol} \cdot \mathrm{L}^{-1}$ respectively) and $\mathrm{xy}$ represent the inorganic content (with respect to the in/or ratio of the last column of table 1: for example $\mathrm{xy}=60$ corresponds to in/or $=60 / 40$ ). The inks with $x y=00$ (three last lines of table 1) are reference solutions of chitosan, without any calcium phosphate inside, whereas the others are made of calcium phosphate particles homogeneously dispersed into a chitosan solution.

$$
\frac{\text { Mass of calcium salt }(g)+\text { Mass of phosphate salt }(g)}{\text { Mass of chitosan }(g)}=\frac{\text { inorganic }}{\text { organic }}
$$


Table 1. Inks studied in this work. "in/or" is used for the inorganic to organic ratio of an ink. The calculated uncertainties are $\pm 0.001 \mathrm{~mol} \cdot \mathrm{L}^{-1}$ on all concentrations.

\begin{tabular}{|c|c|c|c|c|c|c|}
\hline Ink & Calcium salt & $\begin{array}{c}\text { Orthophosphate } \\
\text { salt }\end{array}$ & $\begin{array}{c}\text { Concentration of } \\
\text { calcium } \\
{[\mathrm{Ca}]\left(\mathrm{mol}^{\left.-\mathrm{L}^{-1}\right)}\right.}\end{array}$ & $\begin{array}{c}\text { Concentration of } \\
\text { phosphorus } \\
{[\mathbf{P}]\left(\mathbf{m o l}^{\left.-L^{-1}\right)}\right.} \\
\end{array}$ & $\begin{array}{c}\text { Concentration of } \\
\text { chitosan [CS] } \\
\left(\text { mol.L } \mathbf{L}^{-1}\right)\end{array}$ & $\begin{array}{c}\text { Initial } \\
\text { in/or } \\
\text { ratio (wt\%) }\end{array}$ \\
\hline I15-50 & $\mathrm{Ca}\left(\mathrm{NO}_{3}\right)_{2}$ & $\left(\mathrm{NH}_{4}\right)_{2} \mathrm{HPO}_{4}$ & 0.072 & 0.043 & 0.15 & $50 / 50$ \\
\hline I15-60 & $\mathrm{Ca}\left(\mathrm{NO}_{3}\right)_{2}$ & $\left(\mathrm{NH}_{4}\right)_{2} \mathrm{HPO}_{4}$ & 0.108 & 0.065 & 0.15 & $60 / 40$ \\
\hline I15-70 & $\mathrm{Ca}\left(\mathrm{NO}_{3}\right)_{2}$ & $\left(\mathrm{NH}_{4}\right)_{2} \mathrm{HPO}_{4}$ & 0.162 & 0.097 & 0.15 & $70 / 30$ \\
\hline I15-75 & $\mathrm{Ca}\left(\mathrm{NO}_{3}\right)_{2}$ & $\left(\mathrm{NH}_{4}\right)_{2} \mathrm{HPO}_{4}$ & 0.202 & 0.121 & 0.15 & $75 / 25$ \\
\hline I17-60 & $\mathrm{Ca}\left(\mathrm{NO}_{3}\right)_{2}$ & $\left(\mathrm{NH}_{4}\right)_{2} \mathrm{HPO}_{4}$ & 0.121 & 0.073 & 0.17 & $60 / 40$ \\
\hline I17-70 & $\mathrm{Ca}\left(\mathrm{NO}_{3}\right)_{2}$ & $\left(\mathrm{NH}_{4}\right)_{2} \mathrm{HPO}_{4}$ & 0.181 & 0.108 & 0.17 & $70 / 30$ \\
\hline I17-75 & $\mathrm{Ca}\left(\mathrm{NO}_{3}\right)_{2}$ & $\left(\mathrm{NH}_{4}\right)_{2} \mathrm{HPO}_{4}$ & 0.224 & 0.134 & 0.17 & $75 / 25$ \\
\hline I19-70 & $\mathrm{Ca}\left(\mathrm{NO}_{3}\right)_{2}$ & $\left(\mathrm{NH}_{4}\right)_{2} \mathrm{HPO}_{4}$ & 0.206 & 0.123 & 0.19 & $70 / 30$ \\
\hline I19-80 & $\mathrm{Ca}\left(\mathrm{NO}_{3}\right)_{2}$ & $\left(\mathrm{NH}_{4}\right)_{2} \mathrm{HPO}_{4}$ & 0.312 & 0.187 & 0.19 & $80 / 20$ \\
\hline I15-00 & 0 & 0 & 0.072 & 0.043 & 0.15 & 0 \\
\hline I17-00 & 0 & 0 & 0.108 & 0.065 & 0.17 & 0 \\
\hline I19-00 & 0 & 0 & 0.162 & 0.097 & 0.19 & 0 \\
\hline
\end{tabular}

\section{Rheological behavior of chitosan-calcium phosphate inks}

The rheological measurements of inks were carried out using a TA Instruments Discovery HR-1 rheometer with $40 \mathrm{~mm}$ parallel plate geometry, $1 \mathrm{~mm}$ gap and a solvent trap to prevent drying. Three kinds of tests were performed on each ink:

1. Amplitude sweep test in the range $1-100 \%$ of strain, in dynamic conditions, at $0.1 \mathrm{rad} . \mathrm{s}^{-1}$ and at $25^{\circ} \mathrm{C}$. The output of the test is the evolution of moduli $\left(G^{\prime}, G^{\prime \prime}\right) v s$. oscillation strain. This test allows the identification of solid-like $\left(G^{\prime}>G^{\prime}\right.$ ') or liquid-like behavior regions, the linear viscoelastic region (LVR, where both G' and G', remain constant) and to determine the yield stress $\sigma_{y}$ in solid-like inks according to equation (2) [39].

$$
G^{\prime}\left(\gamma<\gamma_{c}\right) \cdot \gamma_{c}=\sigma_{y}
$$

Where $G^{\prime}$ is the storage modulus, $\gamma$ is the strain and $\gamma_{\mathrm{c}}$ is the critical strain that delimits the higher end of the LVR.

2. Time tests at a strain of $0.1 \%$ and angular frequency of $0.1 \mathrm{rad} . \mathrm{s}^{-1}$ were performed up to 300 s. The output of such tests is the evolution of storage and loss moduli, $G$ ' and $G$ " $v s$. time. We used such time tests to determine if the material was in a steady state.

3. Flow ramp tests were conducted in continuous mode at shear rates of $10-1000 \mathrm{~s}^{-1}$. The output is either a shear stress $v s$. shear strain rate or a viscosity $v s$. shear rate graph. Curves of shear stress $v s$. shear strain rate were fitted using a power-law model (equation 3). 


$$
\tau=K \dot{\gamma}^{n} \quad \text { or } \quad \log \tau=\log K+n \log \dot{\gamma}
$$

Where $\tau$ is the shear stress, $\dot{\gamma}$ the shear rate, $n$ is the flow exponent (calculated from equation 3 ) and $K$ is a scaling factor also known as the flow consistency index [40, 39]. The value of $n$ is an adjusted parameter to fit experimental data to the power-law equation. A physical sense is commonly assigned to its value: if $n=1$, it is a Newtonian fluid; the departure of $n$ from 1 is indicative of less Newtonian behavior; if $n<1$, the fluid presents shear-thinning behavior, that is, viscosity $(\eta=\tau / \dot{\gamma})$ drops as shear increases. For $n>1$, viscosity increases as shear increases: the fluid is said to present shear-thickening behavior $[39,40]$.

\section{3-D printing and characterizations}

The printing machine was a Robocasting system (3DInks, USA). A 3D CAD model of $8 \mathrm{~mm}$ x $8 \mathrm{~mm}$ was designed using the RoboCAD software (3DInks, USA). A syringe barrel of $3 \mathrm{~cm}^{3}$ was filled with one ink at a time. To avoid air bubbles in the ink, it was slowly transferred to a second syringe. Conical nozzle of $400 \mu \mathrm{m}$ internal diameter was used to print all scaffolds.

Printing was performed on a flat and smooth glass substrate immersed in a bath containing sodium hydroxide hydro-alcoholic solution (water 70/ethanol 30) (the $\mathrm{NaOH}$ concentration tested ranged between $0.05 \mathrm{M}$ and $0.40 \mathrm{M}$ ). Instantaneous gelation of the ink was induced by this alkaline bath, while the presence of ethanol made the bath less dense than the ink and prevented the extruded part from floating (as occurred with a bath containing only sodium hydroxide water solution) as suggested in [31]. A set of printing parameters was chosen after a few trial experiments: $400 \mu \mathrm{m}$ for nozzle diameter; $950 \mu \mathrm{m}$ for filament distance in $x$ and $y$ directions on the printing plane; $0.25 \mathrm{M}$ for $\mathrm{NaOH}$ bath concentration; $130-140 \mu \mathrm{m}$ for distance between layers and $9-10 \mathrm{~mm} \cdot \mathrm{s}^{-1}$ for speed ink deposition. In particular, the distance between two successive layers was set between $32.5 \%$ and $35 \%$ of nozzle diameter $(0.4 \mathrm{~mm})$ to favor a good adhesion between the printed layers, whereas the usual values generally used in robocasting of other material inks are in the range of 70-80\% of nozzle diameter.

The temperature of the system was controlled by means of a custom-built enclosure and a convection heater set to $23^{\circ} \mathrm{C}$ while the humidity was measured and varied from 65 to $85 \%$.

Printed hydrogel scaffolds were washed several times with distilled water until the $\mathrm{pH}$ in the final washing water was constant, around 7 . Then, they were stored in water before further characterization.

X-ray diffraction (XRD) analyses were performed using a D8 Advance Bruker AXS diffractometer operated at $40 \mathrm{kV}$ and $40 \mathrm{~mA}$, with CuKa radiation (1.54060 $\mathrm{A}$ ). Scans were acquired in a $\theta-\theta$ configuration, from $4^{\circ}$ to $55^{\circ}$ with a step time of $129 \mathrm{~s}$ and a step size of $0.019^{\circ}$. Phase identification was conducted by comparison to standard patterns from International Center for Diffraction Data Powder Diffraction Files (ICDD-PDF) with the aid of DiffracPlus EVA software (AXS, Bruker). The PDF used for apatite and dicalcium phosphate dihydrate (DCPD) identification were 09-0432 and 09-077 respectively. The obtained diffractograms were normalized with respect to the height of the peak of greatest intensity in the crystalline mineral phase. XRD was performed on chitosancalcium phosphate suspensions. XRD and Scanning Electron Micoscopy (SEM) analysis were also performed on freeze-dried scaffolds. Scaffolds were first immersed for freezing in liquid nitrogen for 1 minute, then the frozen samples were left overnight in a vacuum pump at $0.00 \mathrm{mbar}$ and $86^{\circ} \mathrm{C}$. SEM analyses were performed on gold-coated freeze-dried scaffolds, using imaging with secondary electrons in a JEOL JSM-6010 SEM (USA) at $20 \mathrm{kV}$ acceleration voltage. Optical microscopy analysis was conducted using a Light Axiophot microscope (Zeiss, Germany). Samples of chitosan-calcium phosphate inks were fixed between two glass slides and observed in transmission mode. Size of crystal aggregates was measured using ImageJ software (https://imagej.nih.gov/ij/) using three different $64 \mu \mathrm{m}^{2}$ micrographs for each sample. 
The macroscopic porosity was evaluated by X-ray microtomography, on as-printed samples, using a GE Phoenix v|tome|x s tomograph. The porosity was calculated after selecting a representative volume inside the sample (excluding the edges), thresholding, and simply measuring the white to black voxels number ratio (white voxles: material; black voxel: porosity).

\section{RESULTS}

\section{Chemical composition and microstructure of inks}

The $\mathrm{pH}$ of all inks was about 5.5. It was observed that immediately after mixing salt solutions and chitosan solution, the system was no longer transparent but rather white, indicating the formation of calcium phosphate particles.

The crystalline phase in the inks was investigated by XRD. According to the XRD results (Figure 2a), the peaks corresponding to the principal planes of DCPD (dicalcium phosphate dihydrate: $\left.\mathrm{CaHPO}_{4} \cdot 2 \mathrm{H}_{2} \mathrm{O}\right),(020)$ at $2 \theta=11.681^{\circ},(021)$ at $2 \theta=20.935^{\circ},(041)$ at $2 \theta=29.258^{\circ},(-221)$ at $2 \theta=30.506^{\circ},(220)$ at $2 \theta=34.156^{\circ},(022)$ at $2 \theta=37.105^{\circ}$ were identified. DCPD was the only detectable crystalline phase of calcium phosphates in the inks. No diffraction peaks of chitosan were identified indicating that the amount of crystalline chitosan was below the detection limit. The X-ray diffuse halo observed from approximately $2 \theta=24^{\circ}$ to $36^{\circ}$ in the diffractograms may be attributed to the presence of water (about $96 \mathrm{wt} . \%$ of the ink was water).

Optical micrographs of inks (Figure 2b, example for ink 117-70) showed that they were composed of a dispersed phase, platelet aggregates of DCPD, in a chitosan solution. The dimensions of aggregates were $20 \pm 5 \mu \mathrm{m}$ in length and $14 \pm 5 \mu \mathrm{m}$ in width.

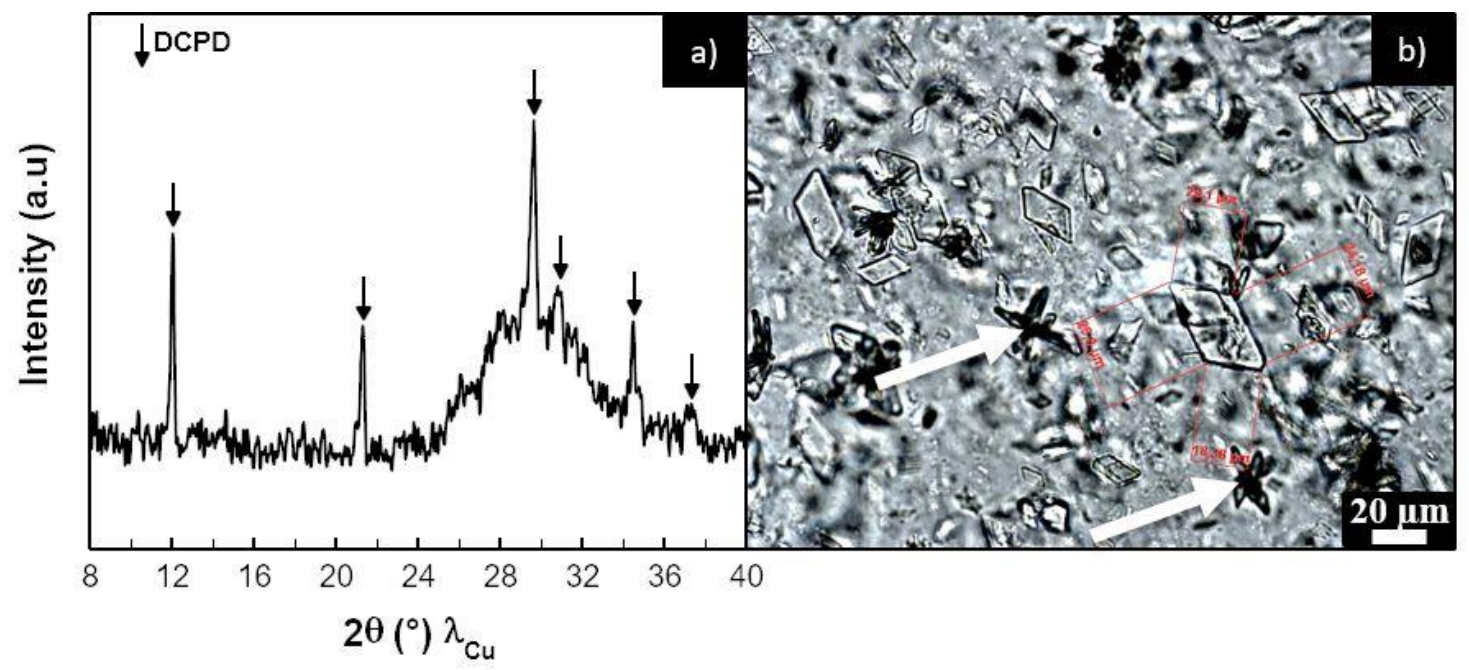

Figure 2: a) Example of X-ray diffractogram of ink I17-70. Black arrows identify the DCPD characteristic planes: (020) at $2 \theta=11.681^{\circ},(021)$ at $2 \theta=20.935^{\circ}$, (041) at $2 \theta=29.258^{\circ},(-221)$ at $2 \theta=30.506^{\circ}$, (220) at $2 \theta=34.156^{\circ}$, (022) at $2 \theta=37.105^{\circ}$. The diffuse halo is assigned to water. b) Example of optical microscopy micrograph of ink I17-70, showing the dispersion of DCPD crystals and aggregates (pointed out by white arrows). The figure 7 also illustrates the size measurement of one DCPD crystal.

\section{Rheology study}

This rheology investigation was conducted to assess whether inks could meet the requirements for robocasting, i.e., shear-thinning and yield stress. Indeed a shear-thinning character facilitates the extrusion through the needle by providing a low viscosity during the high-shear phase encountered by the ink when it flows through the needle. A high enough yield stress (in the rheological sense) enables shape retention of the printed parts for a period of time long enough for physical crosslinking to proceed (less than a few seconds). Other parameters such as high enough G' (that would 
limit sagging of the printed filaments over large spans) will not be discussed here, since only limited span was allowed by the design of the printed parts.

\subsection{Linear viscoelastic region (LVR)}

LVR can be determined by measuring moduli, $G^{\prime}$ and $G$ " as function of strain. Figure 3 shows the results for the different inks.

Observing the region of constant moduli for each ink and for references of chitosan solutions (table 1), LVR strain limit at $0.1 \mathrm{rad} . \mathrm{s}^{-1}$ could be determined as below $10 \%$ in all cases. Thus, all other rheological tests we performed at strains below $10 \%$.
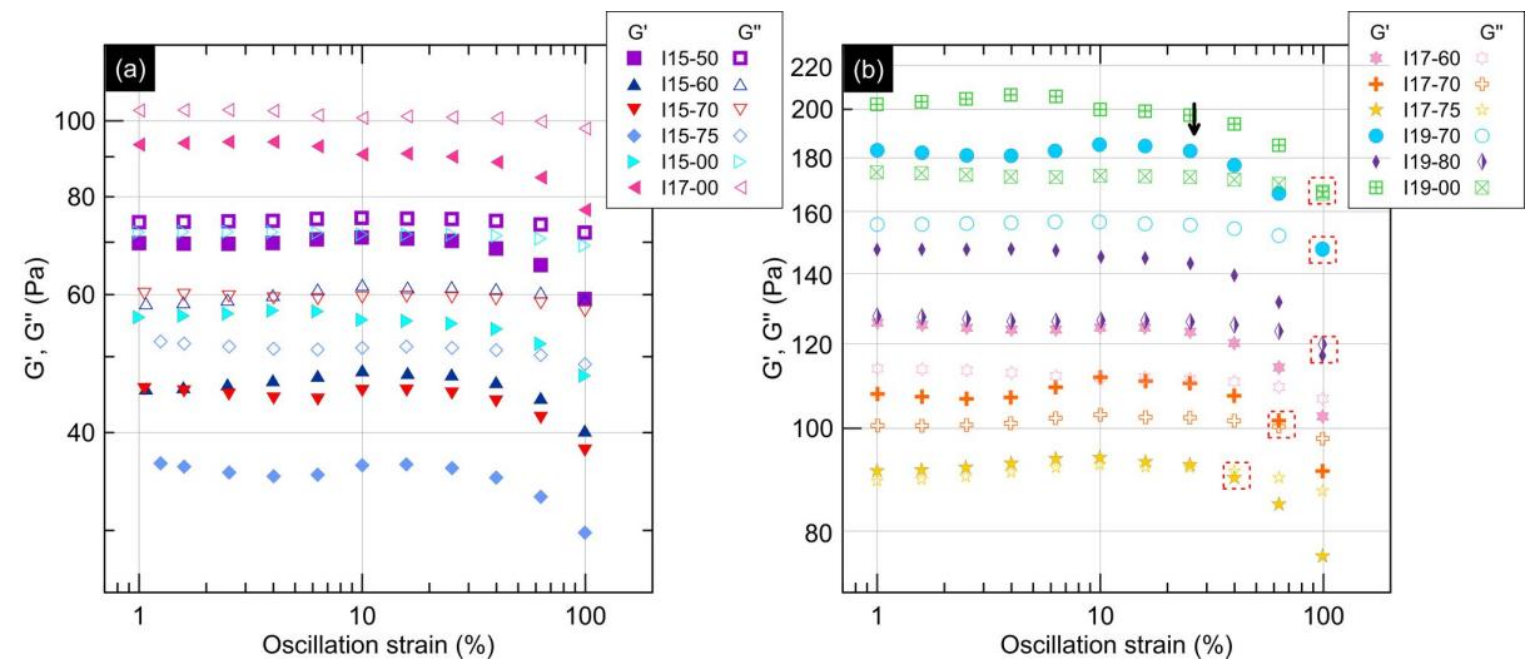

Figure 3: Results of amplitude sweep test (between 1-100\% of strain, at 0.1 rad.s-1) for the different inks and references with (a) liquid-like behaviors and (b) solid-like behaviors. For a detailed description of numbered samples, see table 1. The red square in dotted line indicates the transition point from solid-like to liquid-like. The black arrow indicates the critical strain in ink 119-70.

\subsection{Time sweep experiments}

Another important consideration when testing multiphasic inks is to find out whether the system is in steady state. Figure 4 shows the results of oscillation time test.

It may be observed that moduli remained rather constant over time for all samples, indicating that inks were stable. Values of loss modulus $G^{\prime \prime}$ and storage modulus $G^{\prime}$ are presented in Table 2, column 2 and 3, respectively. From these data, it can be deduced that inks I17-60, I17-70, I17-75, I19-80, I19-70 and I19-00 are solid-like ( $\left.G^{\prime}>G^{\prime \prime}\right)$, while inks I15-50, I15-60, I15-70, I15-75, I1500 and I17-00 are liquid-like $\left(G^{\prime}<G^{\prime \prime}\right)$. Thus, the chitosan concentration largely impacted the viscoelastic properties; an apparent injectable gel state is obtained at the highest concentration at $3.1 \% \mathrm{w} / \mathrm{w}$. 

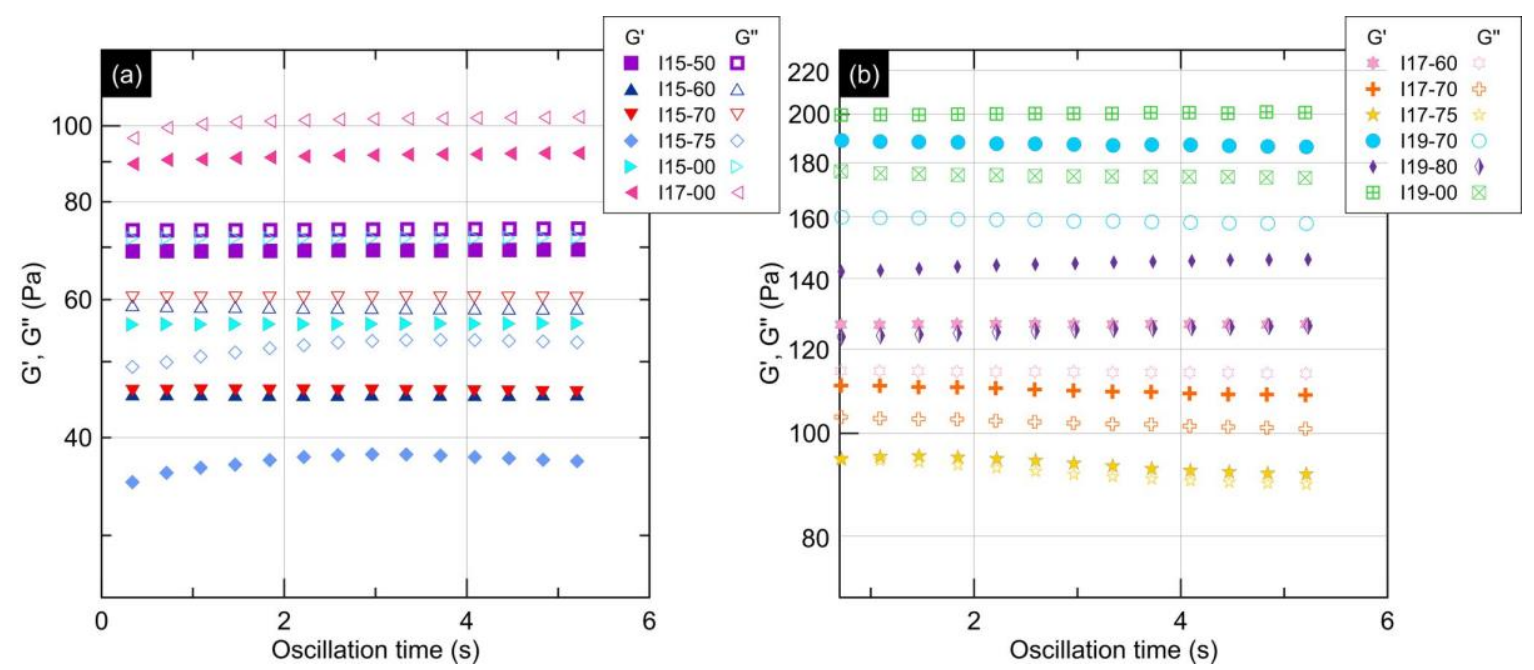

Figure 4: Results of oscillation time test (strain of $0.1 \%$ and frequency of 0.1 rad.s-1 during 300 s) for inks and references with (a) liquid-like behavior and (b) solid-like behavior.

\subsection{Shear-thinning behavior}

Figure 5a shows the rheological curves for chitosan - calcium phosphate inks. Stress-strain rate curves were fitted to equation (2) to estimate values of $K$ (flow consistency index) and $n$ (flow exponent). Values of $n$ much lower than 1 were calculated for all inks, indicating a high shearthinning behavior. Table 2, column 4, summarizes the results.

Shear-thinning behavior can also be observed from viscosity $v s$. shear rate curve. It is characterized by a decrease of viscosity as shear rate increases, as shown in Figure 5b. Thus, all inks met the condition of shear-thinning, as required for robocasting.
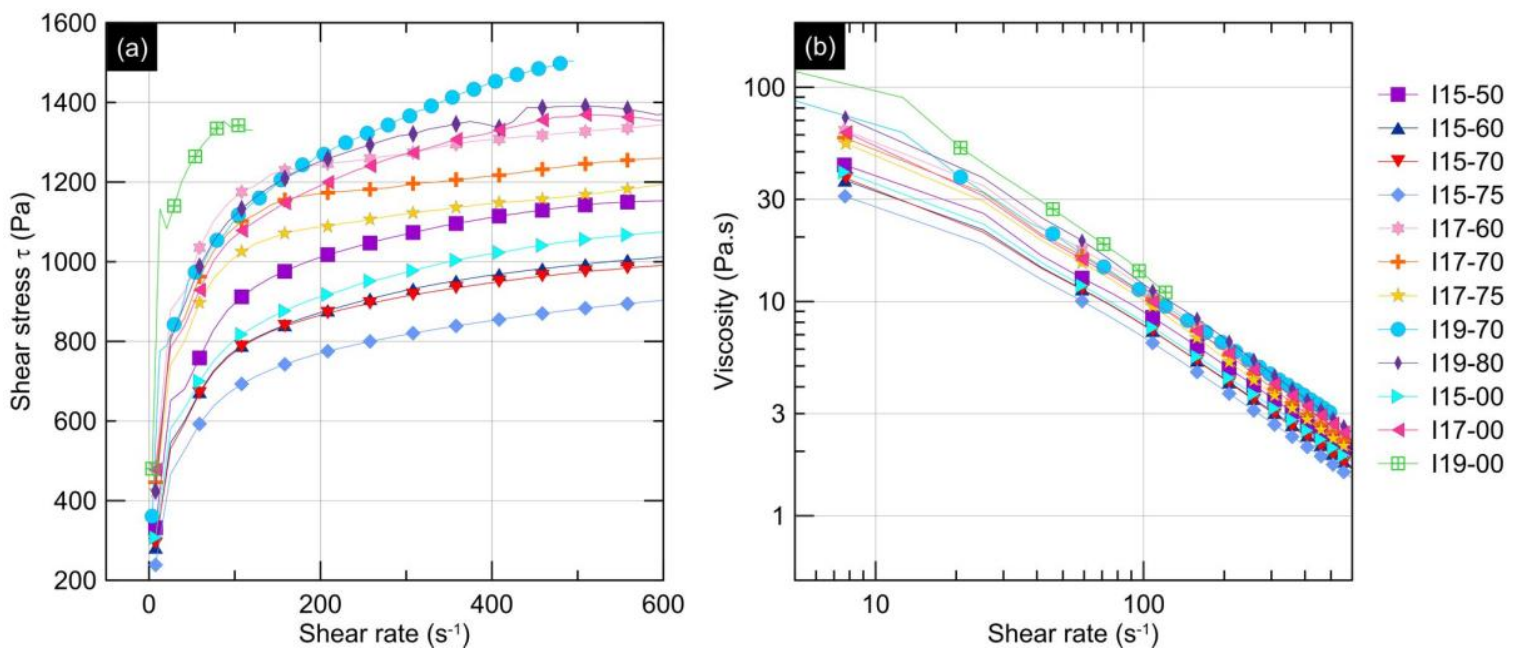

Figure 5: a) Shear stress $v s$. shear rate curve for inks and reference solutions. Data obtained from flow ramp tests conducted at shear rates of 10-600 s-1. b) Shear-thinning behavior: viscosity decreases as shear rate increases. Data obtained from flow ramp tests conducted at shear rates of 10-1000 s-1. Note that for sample I19-00, the flow ramp test results were reported only until shear rate of $120 \mathrm{~s}-1$ because of unexplained instability and lack of reproducibility of the test at higher shear rates. 


\subsection{Yield stress}

In cases of inks I17-60, I17-70, I17-75, I19-80, I19-70 and I19-00 (Figure 3b), the inks were solidlike at low oscillation amplitudes and there was a point beyond which $G^{\prime}$ declined; this was indicative of a breaking of the solid structure to become a fluid, therefore, the material had yield stress. For these inks that showed a well-defined yield stress, values of critical strain and storage modulus were measured from curves of storage and loss moduli vs. oscillation strain, and the corresponding values of yield stress were calculated with equation (2). The results are shown in Table 2 , in column $5\left(\sigma_{y}\right)$.

For all other inks, G" were higher than G' from the start, thus the inks were liquid-like, and calculation of a yield stress was not relevant.

Table 2. Correlation between composition and rheological behavior for all inks. The relative uncertainties on G', G', and viscosities varied between 8 and $15 \%$, and are plotted in Figure 9.

\begin{tabular}{|c|c|c|c|c|c|c|c|}
\hline 1 & 2 & 3 & 4 & 5 & 6 & 7 & 8 \\
\hline Ink & $\begin{array}{l}\text { G" } \\
(\mathbf{P a})\end{array}$ & $\begin{array}{c}\mathbf{G}^{\prime} \\
(\mathbf{P a})\end{array}$ & $\mathbf{n}$ & $\begin{array}{c}\sigma_{y} \\
(\mathbf{P a})\end{array}$ & $\begin{array}{c}\text { Ionic } \\
\text { strength } \\
\left(\mathrm{mol}^{\left.-L^{-1}\right)}\right.\end{array}$ & $\begin{array}{c}\text { Viscosity } \\
\quad(\text { Pa s) } \\
\dot{\gamma}=1 s^{-1}\end{array}$ & $\begin{array}{c}\text { Viscosity } \\
(\operatorname{Pa~s}) \\
\dot{\gamma}=400 \mathrm{~s}^{-1}\end{array}$ \\
\hline I15-50 & $74 \pm 7$ & $69 \pm 10$ & $0.19 \pm 0.02$ & $*$ & 0.30 & 50 & $2.7 \pm 0.3$ \\
\hline I15-60 & $59 \pm 9$ & $45 \pm 7$ & $0.16 \pm 0.01$ & $*$ & 0.46 & 40 & $2.4 \pm 0.4$ \\
\hline I15-70 & $60 \pm 8$ & $46 \pm 4$ & $0.16 \pm 0.02$ & $*$ & 0.68 & 45 & $2.3 \pm 0.4$ \\
\hline I15-75 & $52 \pm 8$ & $37 \pm 6$ & $0.18 \pm 0.02$ & $*$ & 0.85 & 35 & $2.1 \pm 0.2$ \\
\hline I17-60 & $114 \pm 14$ & $127 \pm 11$ & $0.14 \pm 0.02$ & $26.5 \pm 3.0$ & 0.51 & 150 & $3.2 \pm 0.3$ \\
\hline I17-70 & $102 \pm 8$ & $110 \pm 17$ & $0.14 \pm 0.02$ & $24.1 \pm 2.3$ & 0.76 & 65 & $3.0 \pm 0.3$ \\
\hline I17-75 & $92 \pm 11$ & $93 \pm 12$ & $0.14 \pm 0.01$ & $20.9 \pm 2.2$ & 0.94 & 60 & $2.8 \pm 0.4$ \\
\hline I19-70 & $159 \pm 21$ & $188 \pm 28$ & $0.21 \pm 0.03$ & $38.4 \pm 3.5$ & 0.87 & 95 & $3.6 \pm 0.5$ \\
\hline I19-80 & $125 \pm 11$ & $144 \pm 16$ & $0.13 \pm 0.02$ & $30.5 \pm 2.7$ & 1.31 & 85 & $3.5 \pm 0.3$ \\
\hline I15-00 & $72 \pm 10$ & $56 \pm 7$ & $0.16 \pm 0.02$ & $*$ & ----- & 50 & $2.5 \pm 0.3$ \\
\hline I17-00 & $101 \pm 10$ & $91 \pm 10$ & $0.20 \pm 0.02$ & $*$ & ----- & 75 & $3.3 \pm 0.4$ \\
\hline I19-00 & $175 \pm 18$ & $200 \pm 20$ & $0.23 \pm 0.03$ & $26.4 \pm 2.14$ & ----- & 200 & $3.5 \pm 0.4$ \\
\hline
\end{tabular}

* Not measured because inks are liquid-like thus not adequate for robocasting

\section{3-D printing of scaffolds}

To design the robocasting processing, three major key-points must be addressed: ink rheological properties (stability, shear-thinning behavior and yield stress), machine parameters and printing environment.

All inks were prepared at acidic $\mathrm{pH} \sim 5.5$, they were stable, presented shear-thinning behavior and inks with high chitosan concentrations presented yield stress, as shown in the preceding section. As a result, scaffolds from all inks were successfully printed up to five layers (final width of printed sample: $2 \mathrm{~mm}$ ). However, printing more than five layers was difficult, since the printed filament had not the necessary stiffness to support the weight of the layers printed above.

The macroscopic porosity was evaluated by X-ray microtomography (figure 6), and lead to $22 \%$ porosity. However this figure is very unprecise, in particular due to the unprecise sample geometry. 
Besides, figure 6 allows the observation of the sample architecture. Due to the small interlayer distance ( $\max 35 \%$ of the nozzle diameter), only vertical channels were detected (perpendicular plane XY shown in figure 6a), whereas the filaments from successive layers were pressed together to close horizontal channels (perpendicular to the $\mathrm{XZ}$ and $\mathrm{ZY}$ planes). As a result no overhanging structures were created, allowing printing with small values of $G^{\prime}$ as stated above.
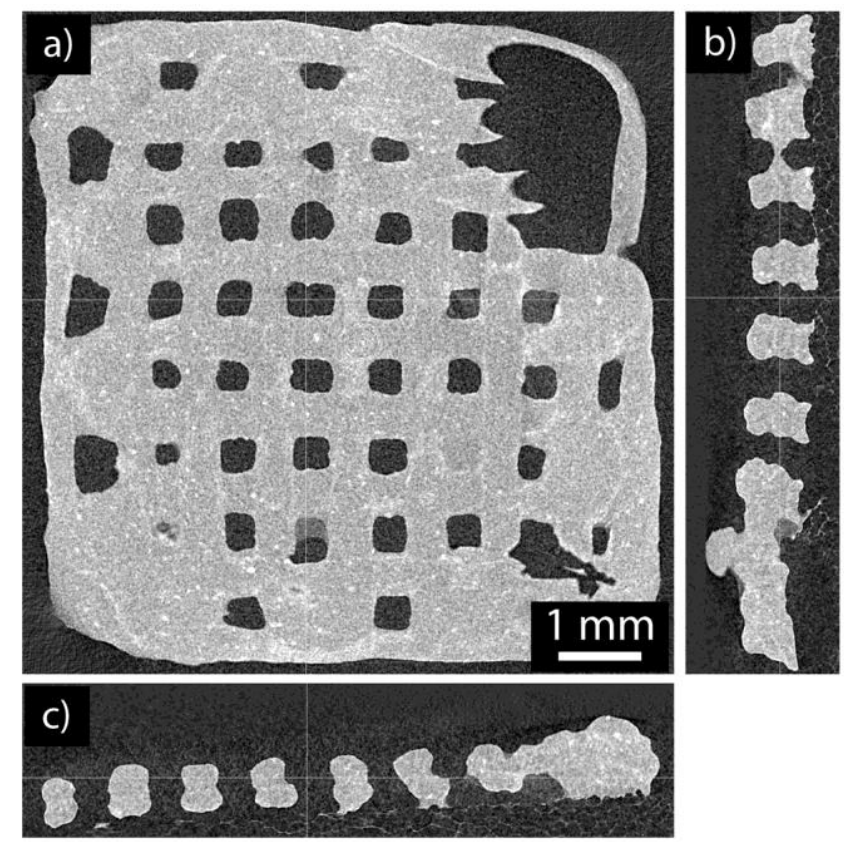

Figure 6: Tomography view of sample printed from ink I19-80. a): plane (XY) view; $b$ ) and c): $X Z$ and $Y Z$ cross sections on the plane indicated by the yellow reticule in a).

4. Characterization of printed scaffolds

From XRD analyses of freeze-dried printed scaffolds, apatite was identified as inorganic crystalline phase (Figure 7). A X-ray diffuse halo (between $2 \theta=8^{\circ}$ and $22^{\circ}$ ) can be observed, and it was attributed to chitosan; other peaks corresponded to the reflection lines of apatite, (002) at $25.879^{\circ}$, (211) at $31.774^{\circ}$ and (112) at $32.902^{\circ}$. Peaks were broad and not very well defined in spite of inorganic/organic ratios up to $80 / 20$.

XRD of scaffold made from ink I15-50 did not show any peak of apatite but a X-ray diffuse halo (between $24^{\circ}$ and $34^{\circ}$ ) of somewhat amorphous structure.
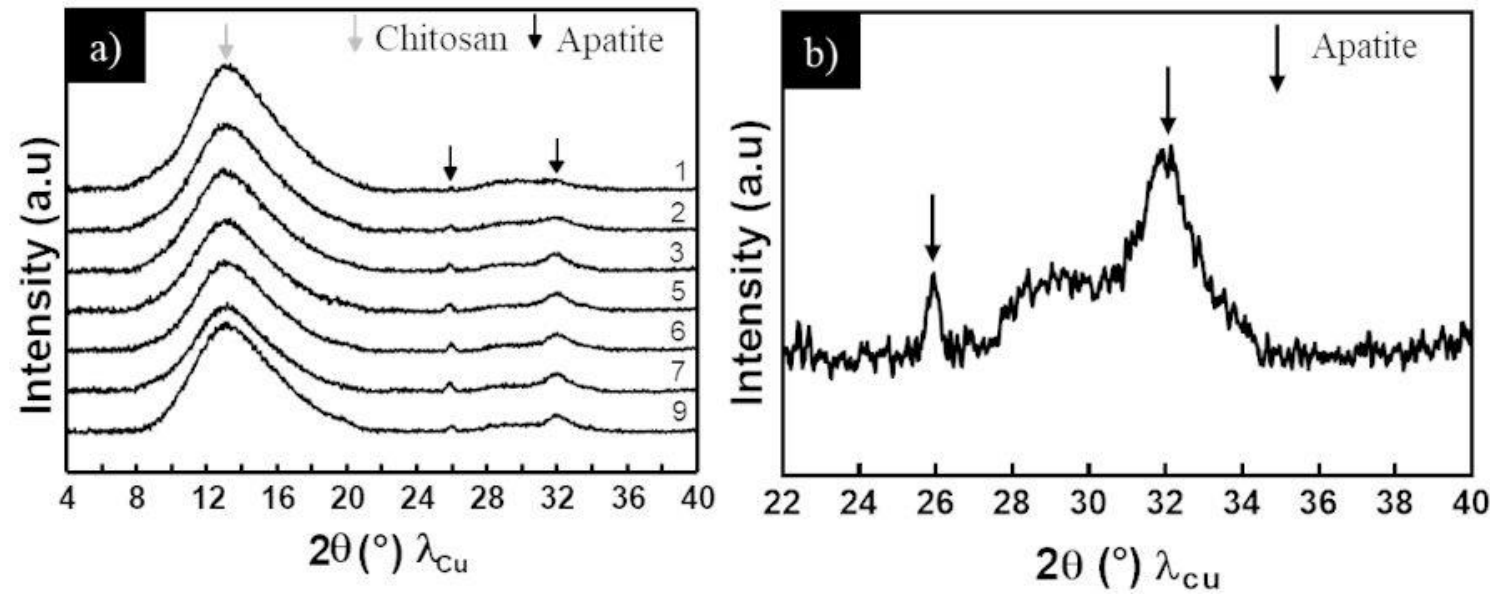

Figure 7: a) Examples of X-ray diffractograms of fabricated scaffolds. Gray arrows identify the chitosan X-ray diffuse halo (between $8^{\circ}$ and $22^{\circ}$ ); black arrows identify the apatite characteristic planes (002) at $2 \theta=25.879^{\circ},(211)$ at $2 \theta=31.774^{\circ}$ and (112) at $2 \theta=32.902^{\circ}$. b) Zoom of the $X$-ray diffractogram of ink I17-70. Black arrows identify the apatite characteristic planes (002) at $2 \theta=25.879^{\circ}$, (211) at $2 \theta=31.774^{\circ}$ and (112) at $2 \theta=32.902^{\circ}$. 
SEM analyses of freeze-dried printed scaffolds showed details of the microstructural arrangement of inorganic and organic phases. It consisted in a chitosan polymeric matrix intertwined with calcium phosphate particles. The microstructure of scaffold fabricated with ink I15-50 is shown in Figure 8 . The micrograph a) showed a well-defined grid. Aggregates of calcium phosphates (white arrows in Figure 8) embedded in chitosan filaments were observed in micrographs b), c) and d). In micrographs c) and d), single platelets of calcium phosphate of different sizes can be observed. Some of the largest platelets were $10 \mu \mathrm{m}$ wide and $20 \mu \mathrm{m}$ long, whereas others were around 10 times smaller (around $0.7 \mu \mathrm{m}$ wide and $2 \mu \mathrm{m}$ long).

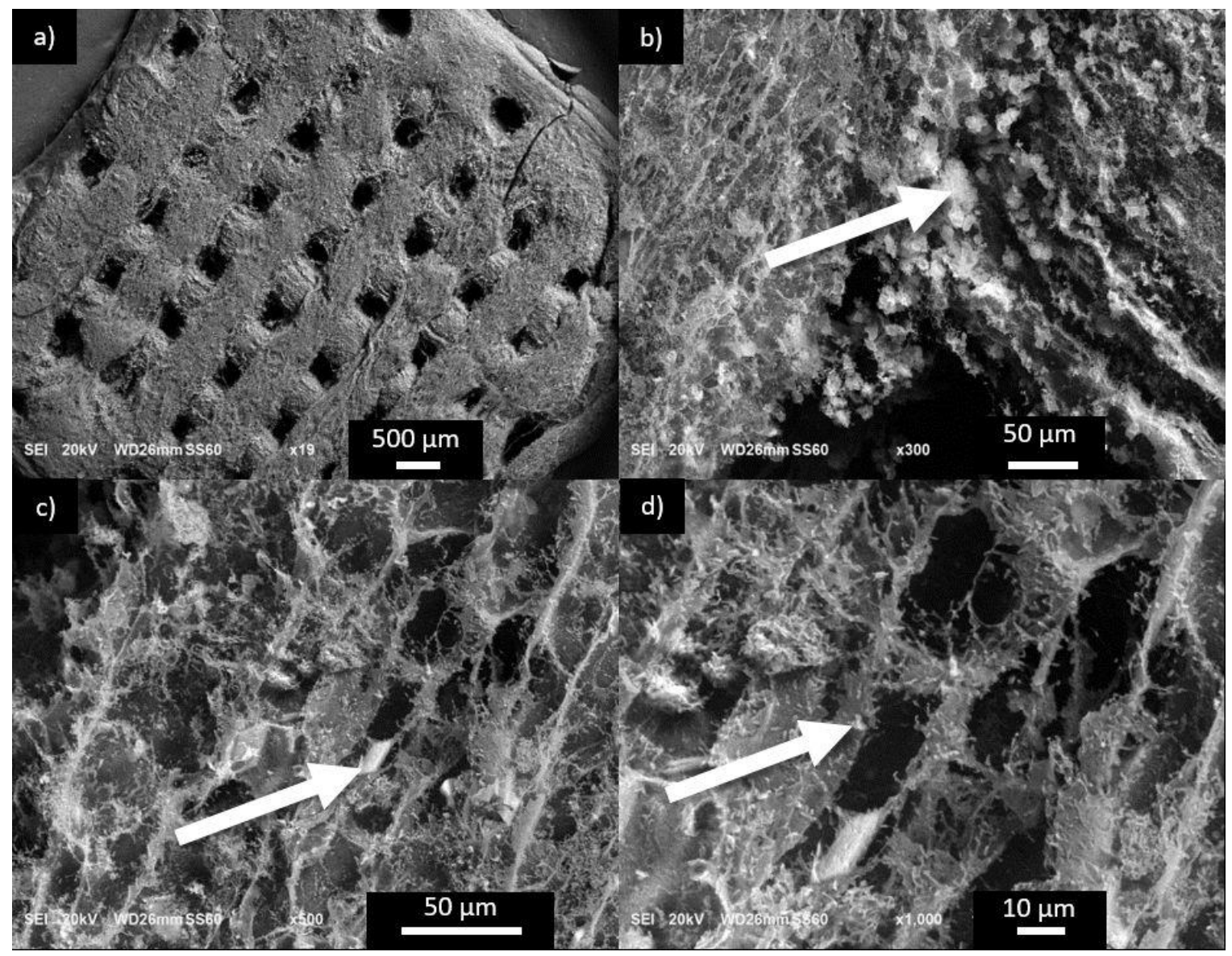

Figure 8: SEM micrographs of scaffolds fabricated with ink I15-50. (a) Well-defined grid of the 3-D printed scaffold and $(b-d)$ calcium phosphate aggregates embedded in chitosan filaments. White arrows indicate the calcium phosphate aggregates in chitosan filaments.

\section{DISCUSSION}

\section{Inks and scaffolds}

The starting materials to fabricate inks were mixed solutions of chitosan, calcium salt and orthophosphate salt (Figure 1). The dissolution of chitosan occurs at $\mathrm{pH} \leq 6$, in an acidic aqueous medium, due to electrostatic repulsions between polymer chains induced by protonated amine groups and hydrophilic interactions [37, 38]

The presence of calcium and orthophosphate salts in solutions at low $\mathrm{pH}$ (here around 5.5 for all inks) induces the spontaneous precipitation of dicalcium phosphate dihydrate, DCPD $\left(\mathrm{CaHPO}_{4} \cdot 2 \mathrm{H}_{2} \mathrm{O}\right)$, as stable calcium orthophosphate [41, 42].

The reaction scheme for DCPD formation could be as follows:

$$
\begin{aligned}
\mathrm{Ca}\left(\mathrm{NO}_{3}\right)_{2} & \rightarrow \mathrm{Ca}^{2+}+2 \mathrm{NO}_{3}{ }^{-} \\
\left(\mathrm{NH}_{4}\right)_{2} \mathrm{HPO}_{4} & \rightarrow 2 \mathrm{NH}_{4}^{+}+\mathrm{HPO}_{4}{ }^{2-}
\end{aligned}
$$


Calcium and orthophosphate ions are solvated (equations (4) and (5)) in the two initial solutions, which are then simultaneously added into the chitosan solution (Figure 1). At this moment, divalent orthophosphate ions can react: 1) forming DCPD with calcium ions, equation (6); 2) decomposing to form monovalent orthophosphate ions in an equilibrium reaction, equation (7).

$$
\begin{gathered}
\mathrm{Ca}^{2+}+\mathrm{HPO}_{4}{ }^{2-}+2 \mathrm{OH}^{-}+2 \mathrm{H}^{+} \rightarrow \mathrm{CaHPO}_{4} \cdot 2 \mathrm{H}_{2} \mathrm{O} \\
\mathrm{HPO}_{4}{ }^{2-}+\mathrm{H}^{+} \rightleftarrows \mathrm{H}_{2} \mathrm{PO}_{4}{ }^{-}\left(p \mathrm{~K}_{a} \sim 7.2\right)
\end{gathered}
$$

Most of divalent orthophosphate ions, $\mathrm{HPO}_{4}{ }^{2-}$, were expected to form DCPD, although, some should remain in the system due to the equilibrium with monovalent orthophosphate ions, $\mathrm{H}_{2} \mathrm{PO}_{4}{ }^{-}$ (equation (7)). DCPD has a $\mathrm{Ca} / \mathrm{P}$ ratio equal to 1 . Since the amounts of salts were calculated in order to reach a $\mathrm{Ca} / \mathrm{P}$ proportion of 1.67 , it is safe to affirm that solvated calcium ions remained in the chitosan-DCPD inks. On the other hand, DCPD crystals are made of $\mathrm{Ca}^{2+}, \mathrm{HPO}_{4}{ }^{2-}$ ions and water molecules. Thus, chitosan-DCPD interactions may occur in the inks. In particular, electrostatic interactions may occur between the protonated amine groups and divalent phosphate ions. HPO4 ${ }^{2-}$ can form physical cross-links of polymer chains through the simultaneous interaction with protonated amine groups of different chains [43]. In addition, hydrogen bonds may be formed between water molecules of DCPD crystals and hydrophilic groups in chitosan molecules.

After mixing calcium, orthophosphate and chitosan solutions, ionic strength decreased as calcium phosphates precipitated in the form of DCPD, as shown in Figure 2. Since it was difficult to calculate or measure ionic strength after and during calcium phosphates precipitation, the initial ionic strength was chosen as a parameter for inks comparison. As mentioned above, the $\mathrm{pH}$ of inks was about 5.5. For this $\mathrm{pH}$, the initial ionic strength was calculated for all inks and reported in Table 2 , column 6. In these conditions, the inks used here were indeed expected to form a suspension of DCPD particles in a chitosan solution, as shown in Figure 2.

Printing scaffolds in a basic liquid medium permitted to achieve two main goals. The first one was the retention of filament shape after extrusion thanks to gelation process of the chitosan contained in the inks. The second goal, concurrent to gelation process, was the phase transformation of the mineral phase in the extruded filament, from DCPD to apatite. Indeed, at $\mathrm{pH}$ higher than 6.5, apatite is the most stable calcium orthophosphate compound at room temperature [2, 42]. The presence of apatite in the 3-D printed scaffolds was confirmed by X-ray diffraction on composites printed from all inks except from ink I15-50 (Figure 7). For the latter, the X-ray diffuse halos around $2 \theta \approx 26^{\circ}$ and $2 \theta \approx 32^{\circ}$ may indicate the presence of an amorphous inorganic phase (or very poorly crystallized apatite with very small crystalline size). These results could be explained considering that this scaffold was made from the ink with the lowest calcium and orthophosphate concentrations and the lowest inorganic/organic ratio (Table 1); therefore, the amorphous phase dominates the diffractogram in comparison with the other scaffolds. For all inks apatite was poorly crystalline, as was expected for a crystal formation with the conditions used here (room temperature and aqueous medium). Interestingly, SEM observations of the 3-D scaffolds (Figure 8) showed that the mineral crystals were intertwined with the polymer matrix. Some of the aggregates had retained the typical shape (platelet) and sizes (around $20 \mu \mathrm{m}$ in length) of the DCPD crystals observed in the inks before gelation (Figure $2 b$ ). This capacity of shape retention during the phase conversion from DCPD to apatite is an interesting feature, which should be further exploited to optimize the microstructure and the mechanical properties of the 3-D printed scaffolds.

With respect to the potential application as filler for large bone defects, the obtained materials seem adequate: the architecture (large channels) should allow easy invasion by both bone cells and endothelial cells, thus creating the possibility of forming vascularized bone tissue even inside large bone defects. Even though the large scale is not yet present on a single sample, the use of several of them in a large defect is possible. 


\section{Rheology of inks}

Questions about the order of magnitude of shear rate and viscosity of the inks arise, especially under the conditions of robocasting used in this work. We estimated the values of these processing parameters from capillary rheology equations for non-Newtonian fluids.

Equation (8) is valid for flow in pipes/capillaries for fluids of any rheology:

$$
\tau=\frac{\Delta P}{2 L} R
$$

where $\tau$ is the shear stress; $\Delta P / L$ is the pressure drop per unit length of nozzle; $R$ is the radius of the nozzle.

Volumetric flow in pipes can be calculated with the Hagen-Poiseuille equation, modified in the case of a power-law fluid (equation 9):

$$
Q=\frac{\pi R^{3}}{\frac{1}{n}+3}\left(\frac{\Delta P R}{2 K L}\right)^{\frac{1}{n}}
$$

In equation (9), $Q$ is the volumetric flow and the other parameters are defined as in the results section. Volumetric flow can also be calculated with flow velocity of fluid (i.e., rate of ink deposition), $S$, and nozzle diameter, equation (10):

$$
Q=S \pi R^{2}
$$

Combining equations (1), (8), (9) and (10), the shear rate can classically be calculated according to (11):

$$
\dot{\gamma}=\frac{S\left(\frac{1}{n}+3\right)}{R}
$$

Applying equation (11), and taking a value of $n=0.2$, as previously computed for the inks (Table 2), $S=10 \mathrm{~mm} \cdot \mathrm{s}^{-1}$ and $R=0.2 \mathrm{~mm}$ then, the shear rate of flow along the nozzle is evaluated to be $\dot{\gamma}=400 \mathrm{~s}^{-1}$. At this shear rate, a typical shear stress would be $\tau=1100 \mathrm{~Pa}$ (Figure 5a). The pressure drop per unit length can be calculated from equation (8). The result is $\frac{\Delta \mathrm{P}}{\mathrm{L}}=11000 \mathrm{~Pa} / \mathrm{mm}$. Such parameters are quite acceptable for extrusion across the nozzle with a length $\mathrm{L}=30 \mathrm{~mm}$.

From Figure 5b, viscosity can be read at $\dot{\gamma}=400 \mathrm{~s}^{-1}$ and extrapolated at a shear rate close to rest (when filament leaves the nozzle), $\dot{\gamma}=1 \mathrm{~s}^{-1}$. Table 2 (columns 7 and 8) shows the calculated values of viscosity for all inks at those shear rates. Due to shear thinning, inks viscosities at the exit of the nozzle (for $\dot{\gamma}=1 \mathrm{~s}^{-1}$ ) were much higher than inside the nozzle (for $\dot{\gamma}=400 \mathrm{~s}^{-1}$ ): whatever the ink, a factor ranging from 15 to 47 is found between the two values (Table 2). However, the viscosity of the inks at the exit of the nozzle was still significantly lower than viscosities generally reported in the literature to retain the shape of the printed scaffold (viscosity of at least $600 \mathrm{~Pa}$ s would have been required [40]). This is why it was necessary in our case to use a printing bath to gel the chitosan, convert the calcium phosphate into apatite and thus favor the shape retention of the extruded filaments. The drawback of this approach is the difficulty to measure the viscosity and the properties of extruded filaments during their evolution in the printing bath to better assess their capacity of shape retention. Viscosity at the exit of the nozzle may be increased by either adjusting (decreasing) the inorganic/organic ratio, or increasing the chitosan solution concentration (at the cost of much more difficult ink preparation), or adding in the ink some viscosity modifiers, such as pluronic F127 that could provide a physical gelling even before gelling of the chitosan itself. These solutions rather complicate the system and thus have not been tested here.

However, a thorough rheological characterization of the inks before their gelation already enables to draw some interesting conclusions about the effect of the different parameters, which should be optimized in the formulation of such inks. In the following, our discussion will focus on finding correlations between composition of inks (Table 1) and their rheological behavior, based on data reported in Table 2. To illustrate the main trends, some are plotted in Figure 9. 

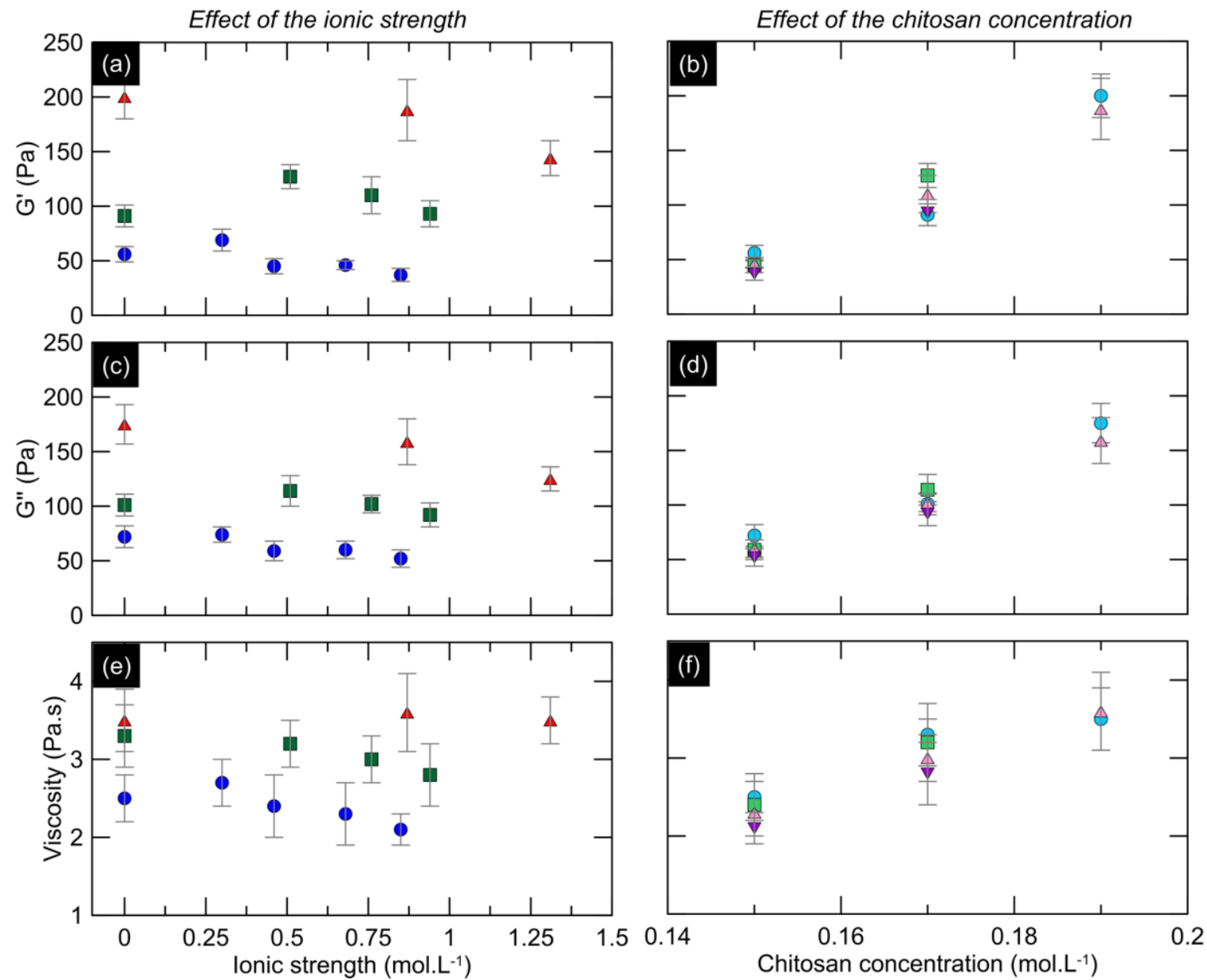

Figure 9: Effect of ionic strength and chitosan concentration on moduli $\left(G^{\prime}, G^{\prime}\right.$ ") and viscosity $\left(\right.$ at $\left.\gamma=400 s^{\wedge}(-1)\right)$. In figures $a), c$ ) and e), circles, squares and triangles correspond to inks with chitosan concentration $0.15 \mathrm{M}, 0.17 \mathrm{M}$ and $0.19 \mathrm{M}$ respectively. Ionic strength equal to zero corresponds to the reference (no organic salts). In figures b), $d$ ) and f), circles, squares, triangles and reverse triangles correspond to inks with inorganic to organic ratio (in/or) of $0 / 100$ (references), 60/40, 70/30 and 75/25, respectively.

The rheological features of the prepared inks (chitosan-DCPD suspensions) fundamentally depended upon composition, $\mathrm{pH}$ and temperature. All inks were at about the same $\mathrm{pH}=5.5$ and all experiments and tests were performed at room temperature. Thus, the concentration of species (chitosan and dissolved ions), and the initial inorganic to organic ratio (in/or) were the only variables from an ink formulation to another.

In the chitosan concentration range used in this work, viscosity of chitosan solutions and viscosity of inks were hundreds of times higher than the viscosity of solvent (water). Therefore, chain entanglements are expected to persist in all inks. The density of chain entanglements is higher as chitosan concentration is higher. Chain entanglement makes the fluid more structured, that is, less Newtonian. The corresponding effect of chain entanglement on rheological properties will be named effect 1: increase in chain entanglement density: higher entanglement density will lead to a solid-like structure with higher G', yield stress and viscosity values, and the system will show more shear-thinning behavior [44-46].

Inorganic to organic ratio was directly related with the mineral content (DCPD particles) of the ink and with the concentration of dissolved ions in the system. It is expected that, as the mineral content increases in a composite ink, it becomes more structured, more solid-like, with the corresponding effect on rheological properties called effect 2: increase in mineral content. As mineral content increases, the fluid would also be more shear-thinning and present higher storage modulus and viscosity, with higher probability of showing yield stress [33]. 
On the other hand, the concentration of dissolved ions also determines the ionic strength of the ink. Screening of electrostatic interactions may occur as an effect of ionic strength, reducing the repulsive forces between chitosan polymer chains. Therefore, the fluid becomes less structured (more Newtonian) and more fluid-like with the corresponding effect on rheological properties: effect 3: increase in ionic strength: at higher ionic strength, elastic properties $\left(G^{\prime}\right)$, shear-thinning behavior and viscosity decrease [33].

It should be noticed that in/or ratio induces two opposite tendencies: as in/or ratio increased, both mineral content and ionic strength increased. As in/or ratio increased, structured fluid nature increased by increasing mineral content and decreased by increasing ionic strength. The observed rheological features were the result of these two opposite effects.

Experimental results can be discussed according to the effects listed above. The effect of chitosan concentration alone can be analyzed in view of the results obtained for references inks I15-00, I1700 and I19-00 (Table 1). As chitosan concentration increased, chain entanglement density increased. Therefore, effect 1 would be expected. Indeed, the chitosan solution changed from liquidlike at concentrations of $0.15 \mathrm{M}$ and $0.17 \mathrm{M}$, to solid-like fluid at concentration of $0.19 \mathrm{M}$ (Table 2). Yield stress was observed only in the most concentrated sample. Viscosity tended to increase as chitosan concentration increased (Table 2, column 7). It was also observed that chitosan solution of all concentrations showed shear-thinning behavior and that shear-thinning behavior was higher as chitosan concentration increased (the absolute value of slope of viscosity $v s$. shear rate curve increased with chitosan concentration). That is, as the chitosan concentration increased, the fluid became more structured.

Inks with the same chitosan concentration and increasing in/or ratio would be expected to have a higher mineral phase content and a higher ionic strength. For the higher mineral content, effect 2 is expected; for the higher ionic strength, effect 3 is expected to change the rheological properties of the inks.

Inks I15-50, I15-60, I15-70 and I15-75 had chitosan concentration of 0.15 M and increasing in/or ratio (Table 1). Results showed an increase in the computed ionic strength and an experimental decrease in storage modulus and viscosity (Table 2, Figure 9c), on the contrary to what was observed when comparing the properties of ink I15-50 (with the lowest in/or ratio) with those of I15-00 (same chitosan concentration, but no mineral content) (Figure 9c). Therefore, it seems that the structuring of the ink due to the presence of mineral particles (effect 2) was significant for inks with low mineral contents as compared to the chitosan solution alone. For higher in/or ratios, the effect of ionic strength became dominant compared to the effect of mineral content (Figure 9). Inks were liquid-like fluids $\left(G^{\prime \prime}>G^{\prime}\right)$. None of the samples showed yield stress. The value of $n$, indicative of shear-thinning, showed no clear variation, that is, shear-thinning behavior was about the same for inks with the same chitosan concentration.

Inks I17-60, I17-70 and I17-75 have chitosan concentration of 0.17 M (Table 1). Experimental results showed that, in this case also, the effect of ionic strength dominated on the effect of mineral content (Figure 9). But for the inks with the highest chitosan concentrations (I17-60, I17-70 and I17-75), fluids were solid-like $\left(G^{\prime}>G^{\prime \prime}\right)$ and yield stress appeared: effect $I$ was evidenced. However, the yield stress $\sigma_{y}$ decreased significantly as ionic strength increased. That is, yield stress appeared at higher chitosan concentration and its value diminished as ionic strength increased (Table 2). As expected, yield stress significantly depended on the interactions existing inside the inks between the chitosan chains, solvated ions and mineral particles.

On the contrary, no significant change in shear-thinning behavior in the inks I17-60, I17-70 and I17-75was observed.

Inks I19-80 and I19-70, at chitosan concentration $0.19 \mathrm{M}$ and decreasing in/or ratio and ionic strength, showed that experimental results led to the same discussion as for inks I17-60, I17-70 and I17-75 (Table 2, Figure 9).

Inks with the same in/or ratio and increasing chitosan concentration and ionic strength would have increasing chain entanglement and higher screening of electrostatic interactions. For the higher chain entanglement density, effect 1 was expected; for higher ionic strength, effect 3 was expected. The groups formed by inks (I15-60, I17-60); (I15-70, I17-70, I19-70); (I15-75, I17-75) had a single 
in/or ratio and increasing chitosan concentration and ionic strength in each group of inks (Table 1). Experimental results showed that storage modulus, yield stress and viscosity increased (Figure 9d, Figure 9f). That is, the fluids became more structured, effect 1 dominated on effect 3 . That is, the dominant factor determining rheological properties was the chitosan concentration. The fluids showed more shear-thinning behavior as chitosan concentration increased.

\section{CONCLUSION}

The experimental protocol set up for 3-D printing by robocasting was adequate to fabricate scaffolds from chitosan solution inks and chitosan-calcium phosphate inks at $\mathrm{pH}$ of 5.5 , and to convert the extruded inks into physical hydrogels of chitosan with intertwined particles of apatite, thanks to a $\mathrm{pH}$ change. Thus, the calcium phosphate phase evolved from dicalcium phosphate dihydrate in the extruded inks to apatite in the 3-D scaffolds. The chitosan solution was gelled in the meantime, and the chitosan hydrogel remained amorphous (from XRD analysis). Apatite was poorly crystalline, forming aggregates in platelet shape of micrometric scale with a rather uniform distribution within the polymer matrix of chitosan.

Properties of inks used in this work mainly depended upon two variables of the formulation of the suspensions: chitosan concentration and inorganic to organic ratio. The chitosan concentration determined the polymer chain entanglement. The inorganic to organic ratio determined both the mineral content and the ionic strength in the inks. An increase in the chitosan concentration led to a more structured fluid, i.e. less Newtonian, solid-like in nature, with increased shear-thinning behavior, and viscosity. Chain entanglement and mineral content also made the fluid less Newtonian but an increasing ionic strength, due to charge screening, made the fluid more Newtonian.

The thorough analysis of the relations between composition and rheological properties of inks carried out in this work opens further research directions to tune composition parameters and properties of composite inks suitable to fabricate 3-D printed biocomposite scaffolds.

\section{ACKNOWLEDGMENTS}

The authors are grateful to the JECS Trust for funding (Contract No. 2015101). This work was also supported by the LABEX iMUST (ANR-10-LABX-0064) of Université de Lyon, within the program "Investissements d'Avenir" (ANR-11-IDEX-0007) operated by the French National Research Agency (ANR).

The authors also are grateful to the staff in the Centre of Advanced Structural Ceramics at Imperial College London for the collaboration work. Special thanks to Ezra Feilden and Esther GarcíaTuñon Blanca for the Robocasting machine training.

\section{REFERENCES}

1. Amini AR, Laurencin CT, Nukavarapu SP. Bone tissue engineering: recent advances and challenges. Critical reviews in biomedical engineering. 2012; 40(5): 363-408. doi:10.1615/CritRevBiomedEng.v40.i5.10

\section{Vallet-Regi M. Bio-Ceramics with Clinical Applications. John Wiley \& Sons; 2014.}

3. Philippart A, Boccaccini AR, Fleck C, Schubert DW, Roether JA. Toughening and functionalization of bioactive ceramic and glass bone scaffolds by biopolymer coatings and infiltration: a review of the last 5 years. Expert Review of Medical Devices. 2015; 12(1): 93-111. doi:10.1586/17434440.2015.958075

4. Martínez-Vázquez FJ, Perera FH, Miranda P, Pajares A, Guiberteau F. Improving the compressive strength of bioceramic robocast scaffolds by polymer infiltration. Acta Biomaterialia. 2010; 6(11): 4361-4368. doi:10.1016/j.actbio.2010.05.024 
5. Peroglio M, Gremillard L, Chevalier J, Chazeau L, Gauthier C, Hamaide T. Toughening of bioceramics scaffolds by polymer coating. Journal of the European Ceramic Society. 2007; 27(7): 2679-2685. doi:10.1016/j.jeurceramsoc.2006.10.016

6. Miao X, Lim WK, Huang X, Chen Y. Preparation and characterization of interpenetrating phased TCP/HA/PLGA composites. Materials Letters. 2005; 59(29): 4000-4005. doi:10.1016/j.matlet.2005.07.062

7. Komlev VS, Barinov SM, Rustichelli F. Strength enhancement of porous hydroxyapatite ceramics by polymer impregnation. Journal of Materials Science Letters. 2003; 22(17): 12151217. doi:10.1023/A:1025300617681

8. Miao X, Tan DM, Li J, Xiao Y, Crawford R. Mechanical and biological properties of hydroxyapatite/tricalcium phosphate scaffolds coated with poly(lactic-co-glycolic acid). Acta Biomaterialia. 2008 ; 4(3) : 638-645. doi:10.1016/j.actbio.2007.10.006

9. Peroglio M, Gremillard L, Gauthier C, Chazeau L, Verrier S, Alini M, Chevalier J. Mechanical properties and cytocompatibility of poly( $\varepsilon$-caprolactone)-infiltrated biphasic calcium phosphate scaffolds with bimodal pore distribution. Acta Biomaterialia. 2010; 6(11): 4369-4379. doi:10.1016/j.actbio.2010.05.022

10. Mano JF, Sousa RA, Boesel LF, Neves NM, Reis RL. Bioinert, biodegradable and injectable polymeric matrix composites for hard tissue replacement: state of the art and recent developments. $\begin{array}{lllll}\text { Composites } & \text { Science } \quad \text { and Technology. 2004; 64(6): 789-817. }\end{array}$ doi:10.1016/j.compscitech.2003.09.001

11. Murugan R, Kumar TSS, Yang F, Ramakrishna S. Hydroxyl Carbonateapatite Hybrid Bone Composites Using Carbohydrate Polymer. Journal of Composite Materials. 2005; 39(13): 11591167. doi: $10.1177 / 0021998305048745$

12. Kong L, Gao Y, Lu G, Gong Y, Zhao N, Zhang X. A study on the bioactivity of chitosan/nanohydroxyapatite composite scaffolds for bone tissue engineering. European Polymer Journal. 2006 ; 42(12) : 3171-3179. doi:10.1016/j.eurpolymj.2006.08.009

13. Pighinelli L, Kucharska M. Chitosan-hydroxyapatite composites. Carbohydrate Polymers. 2013 ; 93(1) : 256-262. doi:10.1016/j.carbpol.2012.06.004

14. Ladet SG, Tahiri K, Montembault AS, Domard AJ, Corvol MTM. Multi-membrane chitosan hydrogels as chondrocytic cell bioreactors. Biomaterials. 2011; 32(23): 5354-5364. doi:10.1016/j.biomaterials.2011.04.012

15. Chedly J, Soares S, Montembault A, Von Boxberg Y, Veron-Ravaille M, Mouffle C, Nothias F. Physical chitosan microhydrogels as scaffolds for spinal cord injury restoration and axon regeneration. Biomaterials. 2017; 138: 91-107. doi:10.1016/j.biomaterials.2017.05.024

16. Shi C, Zhu Y, Ran X, Wang M, Su Y, Cheng T. Therapeutic potential of chitosan and its derivatives in regenerative medicine. The Journal of Surgical Research. 2006; 133(2): 185-192. doi:10.1016/j.jss.2005.12.013

17. Kim IY, Seo SJ, Moon HS, Yoo MK, Park IY, Kim BC, Cho CS. Chitosan and its derivatives for tissue engineering applications. Biotechnology Advances. 2008; 26(1): 1-21. doi:10.1016/j.biotechadv.2007.07.009 
18. VandeVord PJ, Matthew HWT, DeSilva SP, Mayton L, Wu B, Wooley PH. Evaluation of the biocompatibility of a chitosan scaffold in mice. Journal of Biomedical Materials Research. 2002; 59(3): 585-590. doi:10.1002/jbm.1270

19. Francis Suh JK, Matthew HWT. Application of chitosan-based polysaccharide biomaterials in cartilage tissue engineering: a review. Biomaterials. 2000; 21(24): 2589-2598. doi:10.1016/S01429612(00)00126-5

20. Dutta PK. Chitin and Chitosan for Regenerative Medicine. New Delhi: Springer India; 2016. doi:10.1007/978-81-322-2511-9

21. Dash M, Chiellini F, Ottenbrite RM, Chiellini E. Chitosan-A versatile semi-synthetic polymer in biomedical applications. Progress in Polymer Science. 2011; 36(8); 981-1014. doi:10.1016/j.progpolymsci.2011.02.001

22. Hench LL, Polak, JM. Third-Generation Biomedical Materials. Science. 2002; 295(5557): 1014-1017. doi:10.1126/science.1067404

23. Ducheyne P, Qiu Q. Bioactive ceramics: the effect of surface reactivity on bone formation and bone cell function. Biomaterials. 1999; 20(23): 2287-2303. doi:10.1016/S0142-9612(99)00181-7

24. Peniche C, Solís Y, Davidenko N, García R. Chitosan/hydroxyapatite-based composites. Biotecnología Aplicada. 2010; 27(3): 202-10

25. Bose S, Vahabzadeh S, Bandyopadhyay A. Bone tissue engineering using 3D printing. Materials Today. 2013; 16(12): 496-504. doi:10.1016/j.mattod.2013.11.017

26. Smay JE, Cesarano J, Lewis JA. Colloidal Inks for Directed Assembly of 3-D Periodic Structures. Langmuir. 2002; 18 (14): 5429-5437

27. Munch E, Franco J, Deville S, Hunger P, Saiz E, Tomsia AP. Porous ceramic scaffolds with complex architectures. JOM. 2008; 60(6); 54-58. doi:10.1007/s11837-008-0072-5

28. Franco J, Hunger P, Launey ME, Tomsia AP, Saiz E. Direct write assembly of calcium phosphate scaffolds using a water-based hydrogel. Acta Biomaterialia. 2010; 6(1): 218-228. doi:10.1016/j.actbio.2009.06.031

29. Billiet T, Vandenhaute M, Schelfhout J, Van Vlierberghe S, Dubruel P. A review of trends and limitations in hydrogel-rapid prototyping for tissue engineering. Biomaterials. 2012; 33(26): 60206041. doi:10.1016/j.biomaterials.2012.04.050

30. M'Barki A, Bocquet L, Stevenson A. Linking Rheology and Printability for Dense and Strong Ceramics by Direct Ink Writing. Scientific Reports. 2017; 7(1): 6017. doi:10.1038/s41598-01706115-0

31. Ang TH, Sultana FSA., Hutmacher DW, Wong YS, Fuh JYH, Mo XM., Teoh SH. Fabrication of 3D chitosan-hydroxyapatite scaffolds using a robotic dispensing system. Materials Science and Engineering: C. 2002; 20(1): 35-42. doi:10.1016/S0928-4931(02)00010-3

32. Fedotov AY, Egorov AA, Zobkov YV, Mironov AV, Popov VK, Barinov SM, Komlev VS. 3D printing of mineral-polymer structures based on calcium phosphate and polysaccharides for tissue engineering. Inorganic Materials: Applied Research. 2016; 7(2): 240-243. doi:10.1134/S207511331602009X 
33. Cho J, Heuzey MC, Bégin A, Carreau PJ. Viscoelastic properties of chitosan solutions: Effect of concentration and ionic strength. Journal of Food Engineering. 2006; 74(4): 500-515. doi:10.1016/j.jfoodeng.2005.01.047

34. Varma AJ, Deshpande SV, Kennedy JF. Metal complexation by chitosan and its derivatives: a review. Carbohydrate Polymers. 2004; 55(1): 77-93. doi:10.1016/j.carbpol.2003.08.005

35. Fadeeva IV, Barinov SM, Fedotov AY, Komlev VS. Interactions of calcium phosphates with chitosan. Doklady Chemistry. 2011; 441(2): 387-390. doi:10.1134/S0012500811120044

36. Wan Y, Creber KAM, Peppley B, Bui VT. Synthesis, Characterization and Ionic Conductive Properties of Phosphorylated Chitosan Membranes. Macromolecular Chemistry and Physics. 2003; 204(5-6): 850-858. doi:10.1002/macp.200390056

37. Montembault A, Viton C, Domard A. Rheometric study of the gelation of chitosan in aqueous solution without cross-linking agent. Biomacromolecules. 2005; 6(2): 653-662. doi:10.1021/bm049593m

38. Venault A, Bouyer D, Pochat-Bohatier C, Vachoud L, Faur C. Investigation of chitosan gelation mechanisms by a modeling approach coupled to local experimental measurement. AIChE Journal 2012; 58(7): 2226-2240. doi:10.1002/aic.12737

39. Franck AJ. Understanding rheology of structured fluids. Book of TA instruments, 1-17, 2004. http://www.tainstruments.com/pdf/literature/AAN016_V1_U_StructFluids.pdf

40. Feilden E, Garcia-Tunon Blanca E, Giuliani F, Saiz E, Vandeperre L. Robocasting of structural ceramic parts with hydrogel inks. Journal of the European Ceramic Society. 2016; 36(10): 25252533. doi:10.1016/j.jeurceramsoc.2016.03.001

41. Dorozhkin SV. Calcium Orthophosphates as Bioceramics: State of the Art. Journal of Functional Biomaterials. 2010; 1(1) : 22-107. doi:10.3390/jfb1010022

42. Mekmene O, Quillard S, Rouillon T, Bouler JM, Piot M, Gaucheron F. Effects of pH and Ca/P molar ratio on the quantity and crystalline structure of calcium phosphates obtained from aqueous solutions. Dairy Science \& Technology. 2009; 89(3-4): 301-316. doi:10.1051/dst/2009019

43. Nilsen-Nygaard J, Strand SP, Vårum KM, Draget KI, Nordgård CT. Chitosan: Gels and Interfacial Properties. Polymers. 2015;7:552-79

44. Calero N, Muñoz J, Ramírez P, Guerrero A. Flow behaviour, linear viscoelasticity and surface properties of chitosan aqueous solutions. Food Hydrocolloids. 2010; 24(6): 659-666. doi:10.1016/j.foodhyd.2010.03.009

45. Desbrieres J. Viscosity of Semiflexible Chitosan Solutions: Influence of Concentration, Temperature, and Role of Intermolecular Interactions. Biomacromolecules. 2002 ; 3(2) : 342-349. doi:10.1021/bm010151+

46. Desorme M, Montembault A, Lucas JM, Rochas C, Bouet T, David L. Spinning of hydroalcoholic chitosan solutions. Carbohydrate Polymers. 2013. 98(1): 50-63. doi:10.1016/j.carbpol.2013.04.070 